Article

\title{
The Transition from Housing Demolition to Conservation and Renovation in Shanghai: Challenges and Countermeasures
}

\author{
Jiangang Shi, Xinru Min, Hongyun Si * $\mathbb{C}$, Daizhong Tang and Wei Miao \\ School of Economics and Management, Tongji University, Shanghai 200092, China; 84067@tongji.edu.cn (J.S.); \\ 1730448@tongji.edu.cn (X.M.); 08078@tongji.edu.cn (D.T.); miaowei@tongji.edu.cn (W.M.) \\ * Correspondence: sihongyun@tongji.edu.cn
}

Received: 17 October 2019; Accepted: 15 November 2019; Published: 18 November 2019

check for updates

\begin{abstract}
In the past few decades, a considerable number of old houses have been demolished in China's urban redevelopment projects, which led to the disappearance of some historic buildings and the relocation of the original residents. Recently, the strategy of housing demolition (HD) in Chinese cities has been replaced by housing conservation and renovation (HCR). However, the transition from HD to HCR is not carried out well. This study aims to explore the key challenges in HCR practice by using a mixed method. Based on the field investigations in pilot projects and semistructured interviews, current HCR practices in Shanghai are summarized, and the four key challenges are identified as: (1) funding shortages; (2) an underdeveloped regulatory environment; (3) a large gap between reality and residents' psychological expectation; and (4) a lack of stakeholders' involvement. Targeted measures are proposed to mitigate the challenges. The findings and suggestions here could provide valuable references for the government when making decisions on sustainable housing conservation and renovation, and may promote urban renewal practices in China and other developing countries.
\end{abstract}

Keywords: housing demolition; conservation; renovation; challenges; countermeasures; Shanghai

\section{Introduction}

Since the 1980s, China has set off a wave of housing demolition (HD) [1,2]. Some historic buildings were demolished because of a neglect for the historical value; the residents living in these buildings were relocated to new houses [3]. These structures include some alleyways (hutong) in Beijing [4,5] and some lane houses (lilong) in Shanghai [1]. As cultural heritage, These buildings are considered to have high historical value [6-8]. More importantly, after long-term development, the residents in these old houses have formed a unique culture with prominent social value $[9,10]$. Therefore, the demolition of these old houses in urban redevelopment projects has been increasingly questioned.

In the 1990s, Shanghai made some attempts to practice housing conservation and renovation (HCR) $[1,11,12]$. The Xintiandi redevelopment project is a typical case from this period. Xintiandi was originally a lane architectural complex. After privately-funded redevelopment, it has now been converted into a commercial landmark and is no longer used for residential purposes [11]. Although the Xintiandi project kept the building shell, it drove the original residents away and had a negative impact on the social network. The connotations of HCR include not only conserving the physical building, but also protecting social networks and culture [13]. However, half-HCR is aimed at gaining economic profits and usually pays less attention to residents' interests and community culture. Therefore, the Xintiandi redevelopment was only half-HCR, not real HCR.

Around 2016, the Shanghai government decided to protect lane houses, requiring preservation of the original inhabitants, social networks, and cultural traditions. As a result, some policies aimed 
at promoting HCR have been introduced [14]. These policies are aimed at accelerating the transition from HD to HCR. However, in practice, the transition from HD to HCR is difficult to achieve. Only a few projects have launched HCR in Shanghai. This situation also happens in other first-tier cities in China, such as Beijing and Guangzhou, and many developing countries [15-17]. They are also facing the challenges of promoting HCR $[3,18]$. It is important to analyze the problems encountered in HCR practice and propose solutions. Therefore, the specific goal of this study is to examine the current challenges faced by HCR practice and propose some countermeasures.

However, it is difficult to explore the challenges and summarize the practical experience from a national perspective, because the stages of urban development vary significantly across the country. As a megacity in China, Shanghai is a leader in urban renewal and has substantial experience. It is one of the first cities in China to implement large-scale HD and to practice HCR. Therefore, the present study took Shanghai as a case study to examine the key challenges in the transition from HD to HCR. This study attempted to use a mixed method, integrating field investigations, semistructured interviews, and qualitative analysis to summarize current HCR practices, to identify challenges in Shanghai's transition from HD to HCR, and to make some suggestions. Then, this research utilized group discussions and expert argumentation to propose targeted measures. In addition, related literature and government regulations were reviewed throughout the research process.

This paper is organized as follows. Section 2 presents a literature review. Section 3 discusses the research method and process. Section 4 presents the research results and discussion, i.e., current HCR practices, related challenges, and measures to promote current HCR practices in Shanghai. The final section concludes the study and proposes future directions.

\section{Literature Review}

\subsection{HD to HCR in China}

In the 1990s, urban renewal and housing reforms (from physical distribution to full commercialization) provoked large-scale property-led HD in China $[19,20]$. Using Shanghai as an example, urban renewal policies have been introduced since 1991 [21], including the "urban renewal project 365" [22] and redeveloping city villages. At the same time, housing reforms have significantly contributed to developing the real estate market. As a result, many real estate developers cooperated with the government to be involved in urban renewal. The alliance of developers and government demolished old houses and built new commercial houses [23,24].

Previous studies have reported that HD can improve residential living standards [25] and positively impact neighboring property values [26]. However, HD can induce a series of negative impacts on the environment [27] and society [28]. The adverse effects of HD on society prompted the government to transition from HD to HCR. Many scholars believe that HD challenges the maintenance of social sustainability, and has irreparable effects on urban heritage [28,29]. A lack of social sustainability can lead to civil opposition, popular discontent, and social network disruption [30]. Therefore, HD has had some negative effects on social stability, including social conflicts [31] and the disruption of social networks [32]. Moreover, HD has also caused the disappearance of urban historical features [3,33] and the noninheritance of cultural customs [34] to a certain extent. Zacharias et al. (2015) studied Beijing alleyways and found that demolishing the alleyways would decrease public happiness; they also recommended that alleyways in the downtown be conserved because they are part of the urban heritage [5].

Specifically, Shanghai is a "Nationally Famous Historical and Cultural City" of China [35]. Typical historic buildings in Shanghai are lane houses. Lane is a traditional type of housing that represents a fusion of Chinese and Western architectural styles. However, the alliance of local governments and private investors in Shanghai has led to HD, resulting in a conflict between economic growth and heritage conservation [36]. In China, the main goal of carrying out HD is to earn profits through 
secondary land development [22]. Conservation of architectural heritage and traditional culture does not garner much attention. Thus, some lane houses were demolished.

Therefore, there is an increasing interest in housing conservation and renovation (HCR) [15,37], especially for those buildings with historical value [38]. HCR can extend a building's life and offer significant social, cultural, and economic benefits to society [12]. However, a systematic measure has not been already formed to fulfill HCR. Some scholars even suggest a city that preserves urban heritage is a "modern utopia" [13]. However, realizing HCR is in line with UNESCO's recommendations on the historic urban landscape $[18,39,40]$. Some scholars argue that HCR could be smoothly performed through innovative means [13,41,42].

\subsection{Barriers to Implementing HCR Practice}

Previous studies have found that the barriers to HCR practice involve society, economics, and politics.

HCR faces social problems that arise from the transition from HD to HCR. HD and half-HCR underlined economic growth, with less attention paid to social well-being [12]. Hence, the urban neighborhood is excluded from decision-making and profit distribution [11]. Furthermore, economically-led HCR projects may lead to problems such as commodification, gentrification [39], displacement, social exclusion, and heritage dissonance [43]. Therefore, community participation is needed to promote heritage conservation and urban sustainability $[44,45]$. However, community participation in HCR remains underinvestigated. What is worse, the half-HCR of historic buildings may create trans-historical space and confusing architecture, combining historical symbols with modern architecture. As a result, there may be a loss of architectural identity and fragments of history $[46,47]$.

In addition, funding is a critical factor affecting HCR practice. Usually, the government sells heritage resources to the tourism market to create economic profits for funding [48]. However, tourism strengthens the power of local governments and affects the social functions of historic buildings [49]. In other words, excessive attention to economic growth may contribute to unfavorable social problems [22], while extreme attention to social issues may lead to insufficient HCR funding. The key to addressing the funding problem is to increase residents' and social visitors' recognition of the cultural heritage value [50]. Wang and Lee (2008) suggest that local organizations with residential participation can be established to improve the construction environment after the cultural heritage value is recognized. In this way, market competition can be employed to promote growth in HCR funding [51]. However, the specific steps remain unclear.

The government can develop policies to help achieve the transition from HD to HCR. Theodossopoulos (2018) argued that the government can improve HCR by raising awareness, imposing tax incentives, periodically inspecting properties, clarifying statutory identification procedures, and discussing the need for HCR at the national and regional levels [52]. Some researchers have proposed institutionalizing public participation mechanisms. Participants include community, governments, and NGOs. These mechanisms should enable the cooperation of the government and other stakeholders [53,54]. However, the change and enactment of HCR regulations require a lot of arguments and face many difficulties because HCR involves many stakeholders with different claims.

\section{Research Methods}

\subsection{Mixed Research Method}

The mixed research method of this study integrated a literature review, regulations review, field investigations, semistructured interviews, qualitative analysis, group discussions, and expert argumentation.

Reviews of literature and regulations continued throughout the research process. The field investigations and semistructured interviews were conducted between 1 June and 20 August 2018. The field investigations focused on the first batch of HCR pilot projects promoted by the Shanghai 
Municipal Government; these projects include Chunyang Lane and Music Valley in Hongkou District, and Hongshou Lane and Jincheng Lane in Putuo District (as partially shown in Figure 1). Some of these projects have already completed HCR, some are under construction, and others have not yet started HCR. Through field research, the practical conditions were recorded in detail. This is part of the first-hand data in this research. The data format included pictures and recordings.

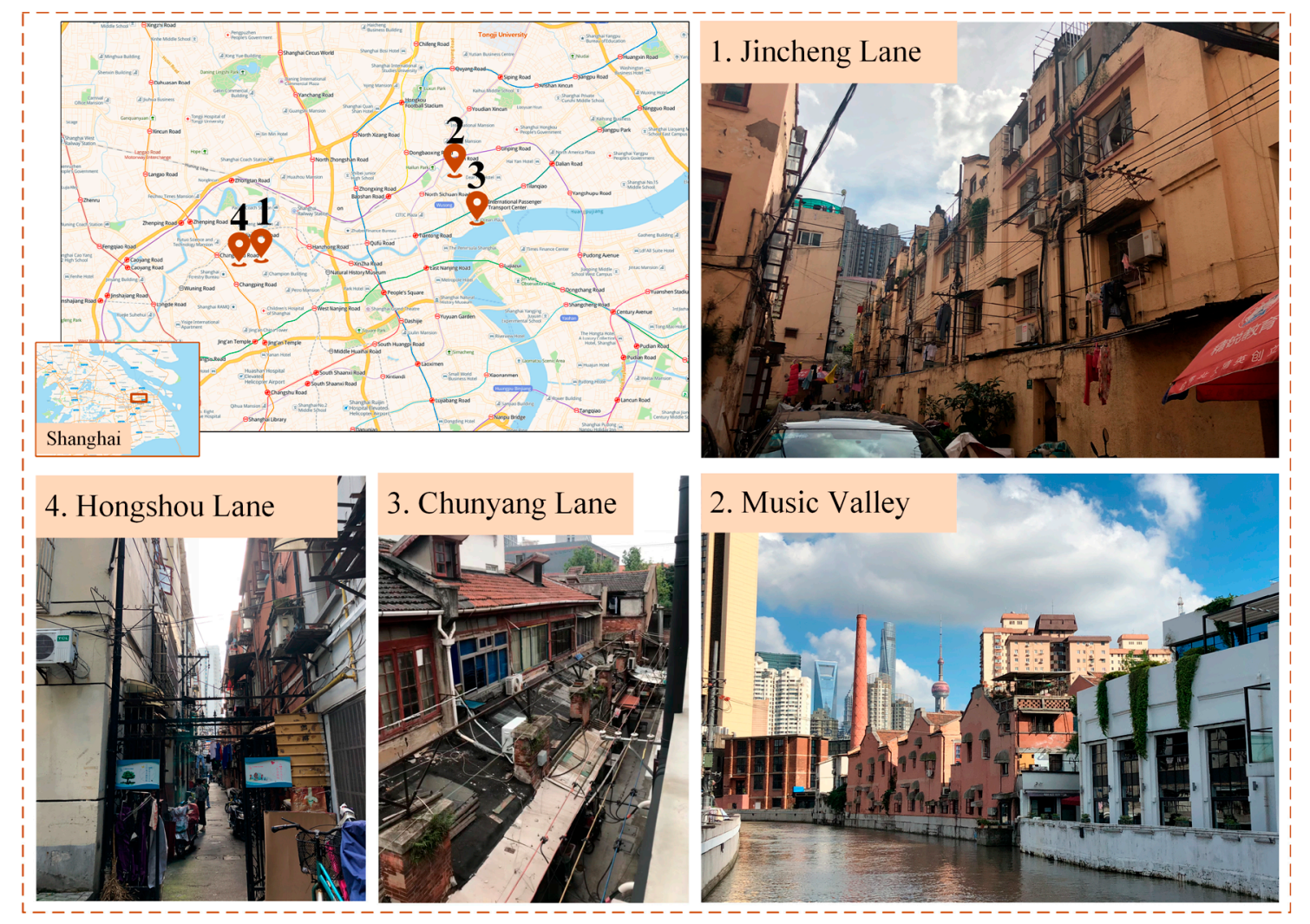

Figure 1. Locations of some of the projects investigated.

The specific interview questions were not clear at the beginning of this study. Therefore, this study adopts semi-structured interviews to collect more first-hand data, because semistructured interviews only need a rough framework of questions in interviews. As shown in Table 1, these questions in this paper related to the Shanghai HCR practice status quo (No. 1, No. 2), prevailing operating modes (No. 3), difficulties in the transition from HD to HCR (No. 4), the cause of the difficulty (No. 5), and potential countermeasures (No. 6, No. 7). These questions were posed to interviewees including civil servants, employees of state-owned and private enterprises, and university researchers. Each individual semistructured interview lasted $30 \mathrm{~min}$ to $1 \mathrm{~h}$; the actual interview duration depended on the interviewees' responses. It was not necessary for every interviewee to answer the questions strictly. Instead, to elicit what they considered important, they were encouraged to share clarification and explanations. This allowed the problems and the experience to be fully shared. The responses of the interviewees in the semistructured interviews were recorded in detail. The data format in this part included the interview minutes and recordings of the interviews. 
Table 1. Major questions presented to the interviewees.

\begin{tabular}{|c|c|}
\hline No. & Questions \\
\hline 1 & $\begin{array}{l}\text { What is the scale of housing in Shanghai that needs to implement HCR? How much money } \\
\text { is needed to implement HCR according to the estimate? }\end{array}$ \\
\hline 2 & $\begin{array}{c}\text { Could you please introduce the housing that needs to implement HCR from the aspects of } \\
\text { physical conditions, historical and cultural values, geographic location, } \\
\text { and property rights? }\end{array}$ \\
\hline 3 & $\begin{array}{c}\text { Could you please explain the operating mode of HCR pilot projects in Shanghai? What is } \\
\text { the reason for implementing this operating mode now? }\end{array}$ \\
\hline 4 & What obstacles do you think the current practice of HCR in Shanghai faces? \\
\hline 5 & What do you think is the reason for the difficulties facing Shanghai from HD to HCR? \\
\hline 6 & What measures do you believe should be taken to solve these obstacles? \\
\hline 7 & $\begin{array}{l}\text { Do you believe there are any profit points in the current HCR projects in Shanghai? What } \\
\text { measures do you believe the government should take to spur private investment? } \\
\text { (presented to the enterprises only) }\end{array}$ \\
\hline
\end{tabular}

Through field research and semistructured interviews, first-hand data was gathered. These data describe in detail the current HCR practices in Shanghai and the difficulties encountered in the actual implementation of the HCR projects. The data also include some suggestions given by the interviewees. The different parts of these data are highly correlated. Therefore, this research used a qualitative analysis to process these data with the help of NVivo12 (as stated in Section 3.2). After a comprehensive and rigorous data analysis, the current HCR practices in Shanghai are summarized; the challenges associated with HCR practice in Shanghai are fully identified; some suggestions for addressing the challenges are also summarized. To develop specific measures, three group discussions were conducted between 23 August and 10 September 2018. Each group discussion lasted 2-3 h. The participants in group discussions were the researchers of this study, including two professors, two doctoral students, and one postgraduate. Group discussions focused on important views extracted from the semistructured interviews; these were used to form a preliminary proposal to solve the challenges in Shanghai's transition from HD to HCR.

After that, expert argumentation was organized during 13 and 20 September 2018. Interviewees in expert argumentation included civil servants and enterprise employees. Participants in the expert argumentation included respondents who presented important points in semistructured interviews. The expert argumentation carried out a specific analysis of the challenges faced by Shanghai, demonstrated the preliminary proposals formed by the group discussions, and finally came up with specific countermeasures.

Table 2 provides details about the interviewees participating in semistructured interviews and expert argumentation. " $\mathrm{S}$ " and " $\mathrm{E}$ " represent participation in semistructured interviews and expert argumentation, respectively. 
Table 2. Expert profiles for the interviews.

\begin{tabular}{|c|c|c|c|c|}
\hline Expert No. & Position & Affiliation & Management Experience (years) & Participation \\
\hline E1 & Division Director & $\begin{array}{c}\text { The Development Research Center of Shanghai } \\
\text { Municipal People's Government }\end{array}$ & $6-10$ & $\mathrm{~S}, \mathrm{E}$ \\
\hline E2 & Division Director & $\begin{array}{c}\text { The Development Research Center of Shanghai } \\
\text { Municipal People's Government }\end{array}$ & $6-10$ & $\mathrm{~S}, \mathrm{E}$ \\
\hline E3 & Deputy Director General & $\begin{array}{c}\text { The Planning and Land Resources Administration } \\
\text { Bureau of Hongkou District }\end{array}$ & $6-10$ & $\mathrm{~S}, \mathrm{E}$ \\
\hline $\mathrm{E} 4$ & Section Chief & $\begin{array}{c}\text { The Housing Security and Housing Administration } \\
\text { Bureau of Hongkou District }\end{array}$ & $6-10$ & $\mathrm{~S}, \mathrm{E}$ \\
\hline E5 & Staff member & $\begin{array}{c}\text { The Housing Security and Housing Administration } \\
\text { Bureau of Hongkou District }\end{array}$ & $3-5$ & $\mathrm{~S}, \mathrm{E}$ \\
\hline E6 & Staff member & $\begin{array}{c}\text { The Housing Security and Housing Administration } \\
\text { Bureau of Hongkou District }\end{array}$ & $3-5$ & $\mathrm{~S}$ \\
\hline E7 & Staff member & $\begin{array}{c}\text { The Housing Security and Housing Administration } \\
\text { Bureau of Hongkou District }\end{array}$ & $3-5$ & S \\
\hline E8 & Deputy Division Director & $\begin{array}{c}\text { The Planning and Land Resources Administration } \\
\text { Bureau of Putuo District }\end{array}$ & $5-8$ & S \\
\hline E9 & Deputy Division Director & $\begin{array}{c}\text { The Housing Security and Housing Administration } \\
\text { Bureau of Putuo District }\end{array}$ & $6-10$ & S \\
\hline E10 & Section Chief & Old Houses Renovation Office of Putuo District & $6-10$ & S \\
\hline E11 & Section Chief & The Culture and Tourism Bureau of Putuo District & $5-8$ & S \\
\hline E12 & Engineer & Taopu Smart Creative City of Lingang Group & $6-10$ & S \\
\hline E13 & Engineer & Zhejiang Xinhu Real Estate Group Co., Ltd. & $6-10$ & S \\
\hline E14 & General Manager & Yuansheng Power Company & $6-10$ & $\mathrm{~S}, \mathrm{E}$ \\
\hline E15 & Engineer & Shanghai Huizhong Engineering Consulting Co., Ltd. & $6-10$ & $\mathrm{E}$ \\
\hline E16 & Engineer & Shanghai Huizhong Engineering Consulting Co., Ltd. & $6-10$ & $\mathrm{E}$ \\
\hline E17 & General Manager & Shanghai Jian'gong Real Estate Co., Ltd. & $6-10$ & $\mathrm{E}$ \\
\hline E18 & Professor & Tongji University & $5-8$ & $\mathrm{~S}$ \\
\hline
\end{tabular}


Combining multiple methods ensures data integrity and objectivity. Figure 2 summarizes the mixed research method and process applied in this study.

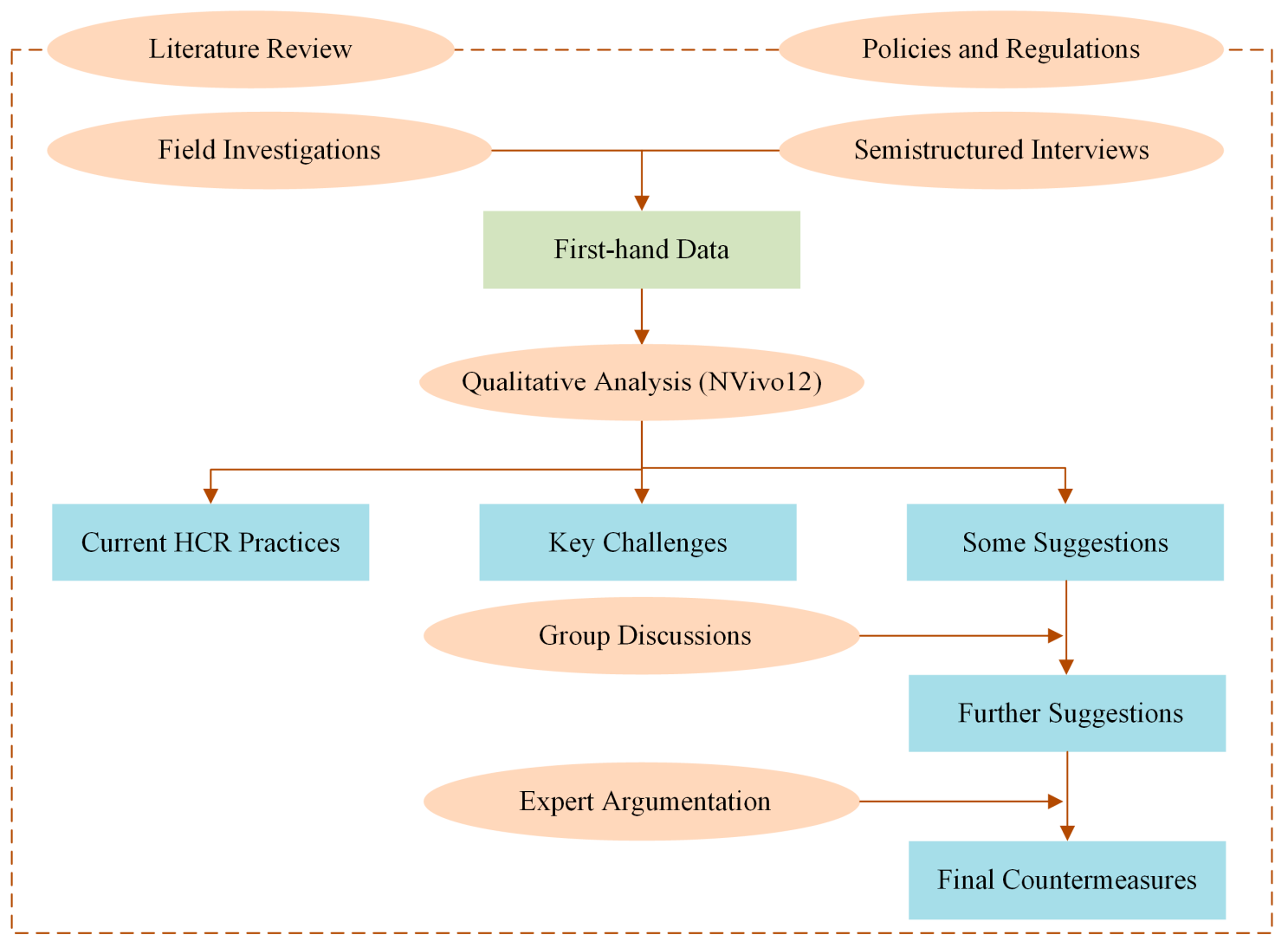

Figure 2. The mixed research method and process.

\subsection{Qualitative Analysis Using NVivo12}

As mentioned in Section 3.1, the first-hand data in this paper included pictures, recordings, and interview minutes. NVivo12 is an important tool used for qualitative analysis in social science. It can be compatible with different formats of data, including text, pictures, audio, and video [55-57]. Therefore, this research processed the data collected in field investigations and semistructured interviews with the help of NVivo12. Data processing involved three steps. The first step was to import all the first-hand data into NVivo12. The second one was creating three main nodes in NVivo12, i.e., HCR practices, challenges, and suggestions. Lastly, to avoid the inaccuracy of automatic coding, manual coding was adopted in this research. The researchers coded the source materials to gather material about the topics and store it in nodes; they discussed each piece of data rigorously to place the first-hand data into the most appropriate nodes. In addition, during the coding process, the analysts supplemented other nodes under the three main nodes. The results are shown in Table 3. 
Table 3. Nodes after coding the first-hand data.

\begin{tabular}{ccc}
\hline Nodes & Sources & References \\
\hline HCR practices & $\mathbf{1 6}$ & $\mathbf{3 3}$ \\
Current practices & 15 & 30 \\
Historical records & 2 & 3 \\
Challenges & $\mathbf{3 0}$ & $\mathbf{1 2 5}$ \\
Funding shortages & 20 & 24 \\
An underdeveloped regulatory environment & 23 & 45 \\
A large gap between reality and residents' & 24 & 32 \\
psychological expectation & 10 & 18 \\
A lack of stakeholders' involvement & 2 & 3 \\
Residents' unwillingness to negotiate & 1 & 1 \\
Inefficient urban planning & 1 & 2 \\
Suggestions & $\mathbf{5}$ & $\mathbf{1 1}$ \\
Revision to HD policy & 2 & 5 \\
Breakthrought in construction planning and FAR & 4 & 6 \\
\hline
\end{tabular}

According to the results, this research deleted the nodes that were mentioned less often, i.e., historical records, insufficient executive staff in neighborhood committees, residents' unwillingness to negotiate, and inefficient urban planning. The deletion of these less important nodes could help the researchers focus on more essential issues. Based on the qualitative analysis via Nvivo12, the current practices and key challenges of HCR in Shanghai are obtained. Meanwhile, even though suggestions were mentioned only 11 times, they were very important to this study. Therefore, based on the two recommendations, i.e., revisions to HD policy, breakthroughs in construction planning and FAR, this research conducted group discussions and expert argumentation to draw the final countermeasures (as stated in Section 3.1).

\section{Results and Discussion}

\subsection{Current HCR Practices in Shanghai}

Shanghai has three methods to deal with old lane houses. The first is to demolish all lane houses and build modern buildings; those modern buildings include commercial houses, office buildings, and commercial real estate. For example, Guangming Lane in Changning District was demolished in 2015, and new restaurants have been built there. The second is to demolish part of the lane. In this case, the undemolished buildings are preserved, while new modern buildings are built on empty land. Usually, retained buildings have high historical value. For example, in 1999, except for valuable lane houses, buildings in Xintiandi were demolished and modern high-rise buildings were subsequently constructed [11]; the retained lane include the site of the First Congress of the Communist Party of China. The goal of these two methods is economic interests; they usually involve the participation of developers and the displacement of the original inhabitants.

The third approach is to preserve all the lane houses on the plot. For example, in the 2018 Hongkou District Chunyang Lane renovation project, all lane houses were retained. In this mode, the government renovates the housing after considering the needs of the original inhabitants. After renovation, the original inhabitants move back. The municipal and district governments bear the repair and resettlement costs.

Over the past few decades, Shanghai has mainly addressed lane housing using the first and second methods, positively impacting economic growth. However, some historic buildings were demolished under the first and second methods. HD has led to the disappearance of historical features and has adversely affected the social network. Therefore, in the past two years, Shanghai has gradually begun to pilot the third approach, striving to preserve historic buildings and social networks. Since 2017, Shanghai has introduced some policies to promote HCR, as shown in Table 4. 
Table 4. Summary of HCR management regulations in Shanghai.

\begin{tabular}{|c|c|c|}
\hline Year & Regulations & Contents Related to HCR \\
\hline 2017 & $\begin{array}{l}\text { The rule for Land Management in } \\
\text { Shanghai's Urban Renewal Planning }\end{array}$ & $\begin{array}{c}\text { To protect urban historic buildings, this rule } \\
\text { demonstrates support for a floor area ratio } \\
\text { (FAR) transfer system and land } \\
\text { supply policies. }\end{array}$ \\
\hline 2017 & $\begin{array}{c}\text { Suggestion on Persisting in } \\
\text { Conservation, Deepening the Organic } \\
\text { Renewal of Shanghai, and Further } \\
\text { Improving the Living Conditions of } \\
\text { the Citizens }\end{array}$ & $\begin{array}{l}\text { This recommendation says that basic } \\
\text { principles include adhering to planning } \\
\text { guidance, government leadership, } \\
\text { voluntary resident participation, and } \\
\text { local conditions. }\end{array}$ \\
\hline 2017 & $\begin{array}{l}\text { Technical Guideline for Rehabilitating } \\
\text { Lane Housing in Shanghai }\end{array}$ & $\begin{array}{l}\text { Technical guidance for conserving and } \\
\text { repairing lane houses in Shanghai. }\end{array}$ \\
\hline 2017 & $\begin{array}{l}\text { Notice on Further Strengthening Old } \\
\text { Housing Renovation in Shanghai } \\
\text { during the 13th Five-Year Plan Period } \\
\text { and Effectively Improving the Living } \\
\text { Conditions of the Citizens }\end{array}$ & $\begin{array}{l}\text { This notice says "further strengthen old } \\
\text { housing renovation during the 13th } \\
\text { Five-Year Plan period. Renovation should } \\
\text { follow the principle of voluntary } \\
\text { participation, government predominance, } \\
\text { adaptation to local conditions, and } \\
\text { diversified funding. Take effective } \\
\text { measures to improve the living conditions } \\
\text { of the citizens." }\end{array}$ \\
\hline 2017 & $\begin{array}{l}\text { Suggestion on Deepening the Organic } \\
\text { Urban Renewal and Promoting } \\
\text { Historic Buildings Conservation }\end{array}$ & $\begin{array}{l}\text { This suggestion proposes setting up special } \\
\text { funds to protect historic buildings and to } \\
\text { promote urban renewal. Special funds can } \\
\text { speed up urban planning formulation and } \\
\text { land support policies; they can also further } \\
\text { improve the support policies for } \\
\text { conservation, renovation, and resettlement. }\end{array}$ \\
\hline 2018 & $\begin{array}{l}\text { Measure on Managing Special Funds } \\
\text { for Historic Buildings Conservation } \\
\text { and Urban Renewal in Shanghai }\end{array}$ & $\begin{array}{l}\text { This measure focuses on the source, use, } \\
\text { and management of special funds. }\end{array}$ \\
\hline
\end{tabular}

Shanghai has put a good deal of effort into implementing HCR in recent years. However, some interviewees reported that Shanghai's HCR practices still need improvement. The transition from HD to HCR is unsatisfying. Although the government's work plan during the 13th Five-Year Plan period indicates that 2.5 million square meters of lane housing should be renovated, only a few projects in Shanghai are implementing HCR, such as Chunyang Lane. Therefore, the transition from HD to HCR is slow.

\subsection{Challenges in the Present HCR Practice}

Based on the field investigations and semistructured interviews, key challenges in Shanghai's transition from HD to HCR were identified. Table 5 summarizes these challenges.

Table 5. Key challenges in Shanghai's transition from HD to HCR.

\begin{tabular}{ccc}
\hline No. & Key Challenges & Number of Interviewees \\
\hline 1 & Funding shortages & 8 \\
2 & An underdeveloped regulatory environment & 15 \\
3 & A large gap between reality and residents' psychological expectation & 10 \\
4 & A lack of stakeholders' involvement & 6 \\
\hline
\end{tabular}


Challenge 1: Funding shortages.

Funding is a precondition for completing HCR. Shanghai has special funds (hereinafter referred to as "special funds") for protecting historic buildings and promoting urban organic renewal. Special funds have been applied to subsidize renovating old houses and protected buildings. However, two interviewees (i.e., E4, E6) indicated that government finances are insufficient to cover all renovation projects.

Interviewees, especially first-line government employees, pointed out that under HD, the predemolition expenses are paid by the district government. However, land-transferring fees paid to the district government are low because the land is planned for commercial use. Recently, commercial real estate has not been as profitable as residential real estate. Therefore, the land-transferring fees of commercial land are lower than those of residential land in Shanghai. The income is insufficient to cover expenses; the district government loses money. After implementing HCR under the current regulatory system, the district government's losses become more serious. With HCR, all expenditures are co-financed by municipal and district governments; those expenditures cover relocation, resettlement, and renovation costs. However, the government receives no land-transferring fees because the right to use the land has not been transferred. For example, in the first phase of the Chunyang Lane project, the government pays all the fees, while residents do not pay. As a result, interviewees believed the Chunyang Lane project is not a sustainable model. They recommended that HCR implementation should involve social funds. They also suggested that special funds should have a flexible channel for injecting capital.

A current urgent issue is addressing the need for other financing sources besides the government. However, from the developers' point of view, the current HCR project is unprofitable, so few developers are willing to invest. This is because the current HCR regulations require preserving both the original inhabitants and the buildings. In this context, developers cannot make a profit. What is worse, renovation costs in HCR are high, and the task is challenging. Considering Hongkou District as an example, the district government plans to implement lane renovations for 5000 households every year; the cost per household is calculated as 300,000 RMB. Thus, nearly 1.5 billion RMB is needed annually. The cost of each household is estimated based on the first phase of the Chunyang Lane project. The third phase of the Chunyang Lane project remains in progress during the writing of this paper, so official data have not already been released. There are 46 households in the first phase of the Chunyang Lane project, and the initial contract price for renovation is 11 million RMB. Considering the cost change and housing subsidy, the average household cost is approximately 300,000 RMB. Despite these numbers, in 2017, Hongkou District's housing security expenditures were only 490 million RMB [58]. Moreover, Shanghai has about 7.3 million square meters of lane housing that needs to be renovated in total, requiring an estimated 2.25 trillion RMB.

Challenge 2: An underdeveloped regulatory environment.

Although Shanghai has introduced some HCR policies, Shanghai did not issue implementation regulations that were sufficiently detailed. For example, many lane houses are located in the area planned for commercial use; they are used as residences if HCR is implemented. In this case, there are no specific guidelines to address inconsistencies between planned and actual use in Shanghai.

Previous studies have highlighted the importance of the government in HCR projects, especially in policy formulation [51,59]. Indeed, 15 interviewees thought the underdeveloped regulatory environment is currently the most serious problem. Shanghai has introduced a series of HCR regulations in the past two years; however, interviewees questioned the operability of these regulations.

The current regulations in Shanghai do not guide HCR practice well. Improvements are needed for different concerns. The first is the need to frame standards to preserve lane houses. Current HCR regulations in Shanghai protect buildings over 50 years old. As a result, many houses of no worth are under protection. These buildings are so dilapidated that renovation will not help them. Therefore, the current standards need adjustment. The second concern relates to new architectural design codes, such as spacing and lighting design codes. This is needed because lane housing cannot 
meet the current architectural design codes. For example, there are no firefighting corridors and staircases in lane houses; such facilities are compulsory in the current codes. The third concern is that there is no detailed institutional design for the FAR transfer; this makes the transfer of FAR between different regions difficult to perform. Most lane houses are downtown and are planned with high FAR; however, the HCR regulations make the planned FAR impossible to achieve. In addition, Shanghai has issued a regulation to allow the FAR to be transferred to different regions; however, the specific steps are not clear.

Challenge 3: A large gap between reality and residents' psychological expectation.

Under the HD policy, residents can receive large amounts of compensation for land expropriation. This money often helps residents buy a new house and can even render them rich. In China, many people have become wealthy because their houses have been demolished; they are called "demolition parvenus" (chai'erdai). Demolition parvenus became rich because of compensation for HD. However, under the current HCR policy, residents receive monthly accommodation subsidies during the repairs. As a result, the HCR policy brings far less direct profit to residents than HD; the comparison between HCR and HD has a significant impact on residents' satisfaction [7,60]. Moreover, residents do not have enough understanding of HCR policy. Some government officials have reported that it is difficult for residents to correctly understand official policies and to comprehend the sociocultural significance of HCR. Therefore, the transition from HD to HCR is unacceptable to most residents.

Two interviewees (i.e., E5, E9) mentioned that in practice, the district government has eased the gap between reality and residents' psychological expectation by two steps. The first was that the neighborhood committee asks residents whether they would like to renovate their houses. The second was that designers ask each household for its specific needs. In this process, the district government needs to do a lot of outreach. Meanwhile, the district government employees need to emphasize persistently to the residents that their houses will not be expropriated. However, this method is time-consuming and difficult to apply widely. Therefore, interviewees recommend that the municipal government should take actions to address this issue.

Challenge 4: A lack of stakeholders' involvement.

Engaging communities in HCR projects can increase social sustainability and facilitate the social inclusiveness of projects [12]. By involving enterprises in HCR projects, social funds can be injected [11]. At the same time, the participation of multiple stakeholders can help innovate new operating modes for HCR.

The Shanghai HCR policy highlights the need to strive for the understanding and support of citizens and society. However, the current HCR practice in Shanghai has not achieved this. The main HCR stakeholder is the government; the participation of multiple stakeholders has not been realized. Almost all the interviewees mentioned that the government has the absolute initiative in HCR practice, while other social stakeholders lack the motivation and channels for participation.

Some interviewees proposed ways to increase multiple stakeholders' involvement in HCR projects. On the one hand, some entrepreneurs have suggested that, as mentioned earlier, companies could be attracted to the process by improving and revising regulations. On the other hand, a general manager (i.e., E14) proposed that design, decoration, rental, and consulting enterprises could be mobilized to improve market participation. At the same time, the government should take measures to activate the lane house sale and rental market to encourage residents' participation.

\subsection{Measures to Promote Current HCR Practice}

Based on the suggestions proposed by interviewees in semistructured interviews, three group discussions were organized to brainstorm possible policy measures. After that, expert argumentation was organized to analyze and discuss these presented measures. As a result, five measures were proposed (as shown in Figure 3). These five recommendations relate to instructional policies (M1, M2, M3), platform construction (M2, M4), and capital operation (M5). These measures can be piloted at the community level and then be transitioned to the urban level. Internal community momentum 
will gradually form sustainable interests and rules, and then achieve sustainable implementation at the urban level [61]. Figure 3 shows the corresponding relationship between each measure and the challenges. Five measures are described in detail below. The thick solid line indicates that the measure focuses on solving the challenge; the thin dotted line indicates that the measure has a positive impact on solving the challenge.

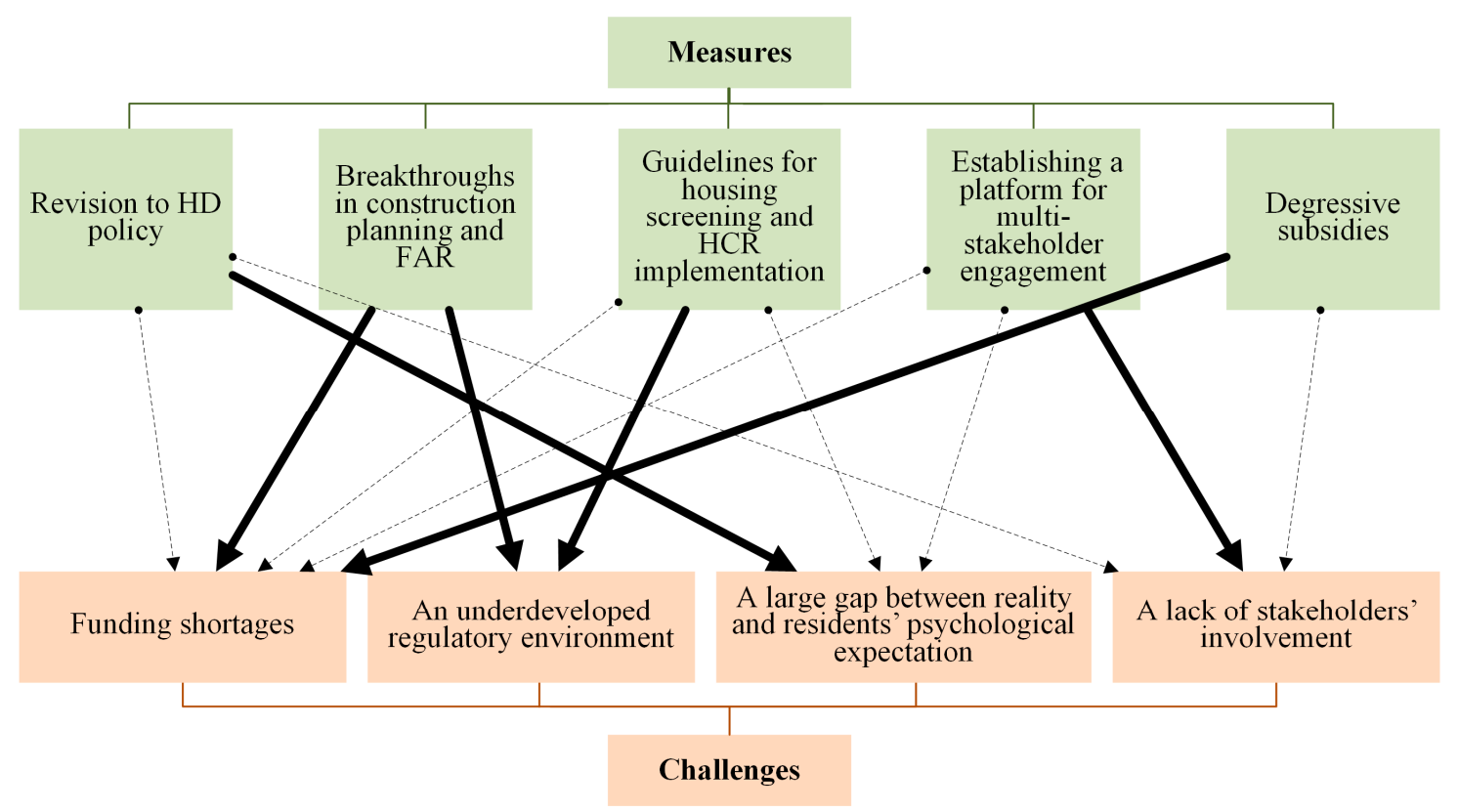

Figure 3. Corresponding relationships between measures and challenges.

Measure 1: Revision to HD policy.

To level out residents' income under HD and HCR, many interviewees advocated for reducing the compensation for housing demolition. Excessive HD compensation in Shanghai has led to the emergence of many demolition parvenus and social conflicts [62]. The government has also invested considerable labor and material resources in HD implementation. At the same time, as Shanghai's land market has entered a stage of stock adjustment, low land-transferring incomes make it difficult for governments to cover HD costs. Therefore, the HD policy should be revised. Relevant departments such as the Housing Administration Bureau, the Planning and Land Resources Administration Bureau, and the Development and Reform Commission need to cooperate and undertake the revision of HD policies, with the main purpose of reducing HD compensation.

In addition, while modifying HD policy, residents should also be educated so that they could understand how the rent or price of lane houses will increase after HCR. In this way, residents would anticipate that they would gain more profits through HCR than HD. This measure can effectively address Challenges 1,3, and 4, especially Challenge 3.

Measure 2: Breakthroughs in construction planning and FAR.

Shanghai's HCR policy needs two types of breakthroughs. The first one is breaking through construction restrictions, including allowing developers to "move" and "cluster" historic buildings. Moving the buildings is technically feasible [63]. Allowing the clustering of lane houses can facilitate land redevelopment because the bits of available land will be gathered together. The developers can thus use the land more efficiently.

The second is that FAR should be allowed to increase appropriately. This means reducing restrictions on building height. Increasing the current FAR could allow enterprises to achieve capital balance [64] and avoid disorderly urban expansion. At the same time, the relevant government departments should formulate a detailed FAR transfer system as soon as possible. The new system should break through the inter-regional FAR transfer restrictions. Furthermore, the new system should 
set methods for transferring planning indicators and determining land status. This measure would establish a FAR trading platform at the municipal and district level (as shown in Figure 4). Through this platform, FAR can be transferred across different districts under the supervision and negotiation of municipal governments. Construction areas and historical blocks could apply for FAR exchange in district platforms, and every district platform would share information on the municipal platform. In this way, the municipal platform could coordinate and organize between different districts and achieve FAR exchange across the whole city. The municipal platform consists of relevant municipal government departments, including the Construction Committee, the Planning and Land Resource Administration Bureau, and the Development and Reform Commission. They supervise the district platforms and control the total FAR amount from the municipal view. If the users of two pieces of land intended to exchange FAR, they could negotiate privately and apply for scheme approval in the district platform. After the scheme is approved, it must be published publicly for supervision. This measure would help solve Challenges 1 and 2.

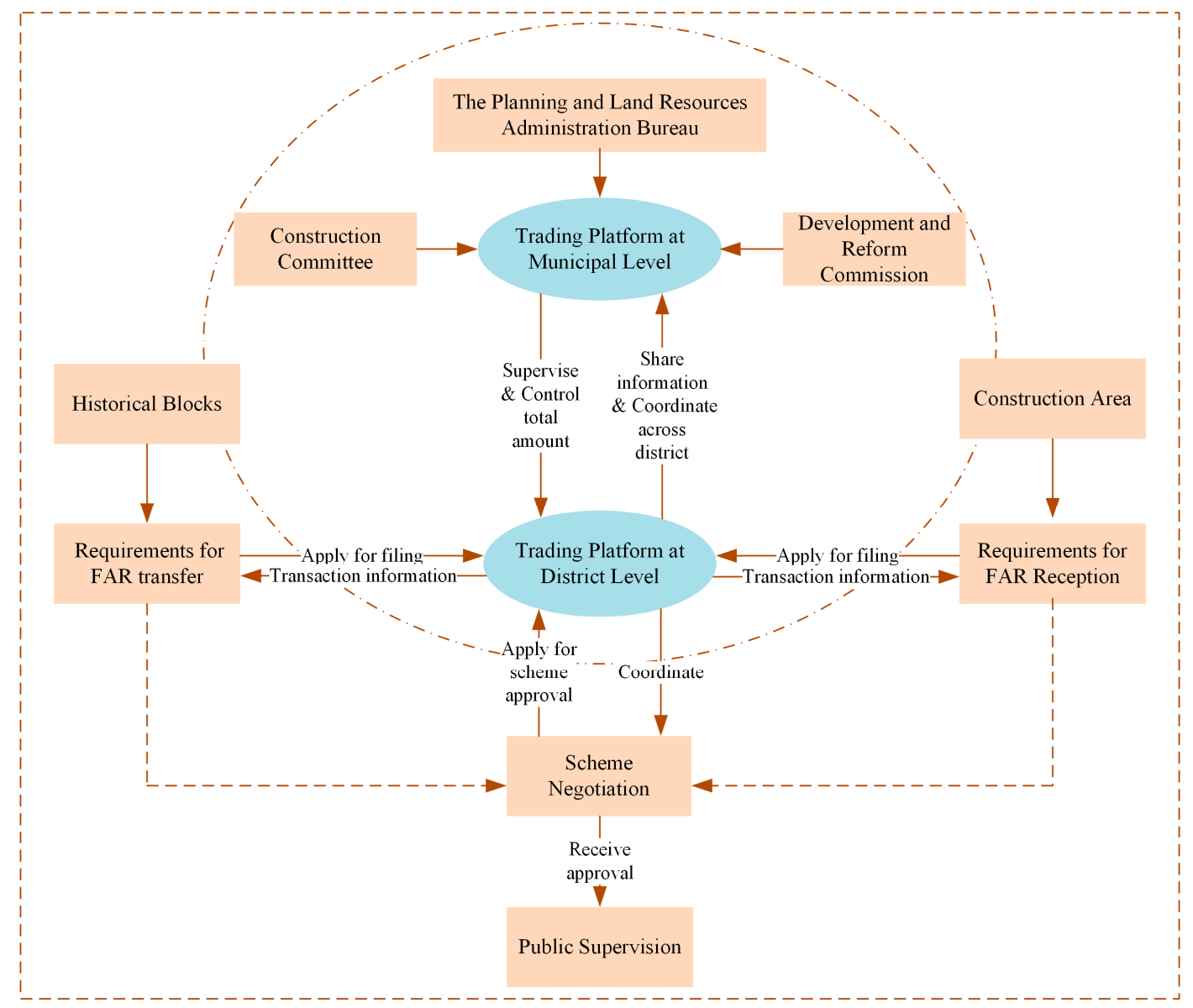

Figure 4. The FAR trading platform at the municipal and district level.

Measure 3: Guidelines for housing screening and HCR implementation.

Several interviewees explained that an important practical problem is that it is unclear whether some plots should be demolished or rebuilt. Therefore, they proposed that detailed guidelines for housing screening should be compiled as soon as possible. In addition, guidelines for HCR implementation should be formulated as soon as possible. For example, relevant government departments should make improvements to existing architectural design codes as quickly as possible based on HCR practices.

For both guidelines, specific implementation details are needed. The key objective is to develop detailed standards for housing screening and HCR implementation so that they can be implemented 
in practice. Implementing Measure 3 would address Challenge 2; Challenges 1 and 3 will also be positively affected.

Measure 4: Establishing a platform for multi-stakeholder engagement.

It is important to realize multi-stakeholder engagement in the process of implementing HCR [65]. To facilitate multi-stakeholder participation, many interviewees believe the government should create a platform for HCR (hereinafter referred to as the "platform"). The platform should integrate design, decoration, financial service, leasing, trade, and other services. In the platform, the government would be responsible for issuing relevant support policies. Residents may independently apply to renovate their houses. Based on the residents' requests, the designer would participate in the feasibility study and develop the renovation plan. In addition, decoration companies could also enter the platform. The neighborhood committee and residents should choose a decoration company together. Furthermore, financial institutions could enter the platform. If residents were to borrow money to pay for the design and decoration of the housing renovation, financial institutions could provide them with special loans. If residents chose to pay with their own money, they could apply to the government for special subsidies (refer to Measure 5). Finally, renovated houses could be rented or sold to all consumers on the platform. In this way, residents could acquire ownership of lane houses; housing ownership plays an important role in improving residents' happiness [66]. The schematic diagram of the platform is shown in Figure 5. This measure is proposed for Challenge 4; it also has a positive impact on Challenges 1 and 3.

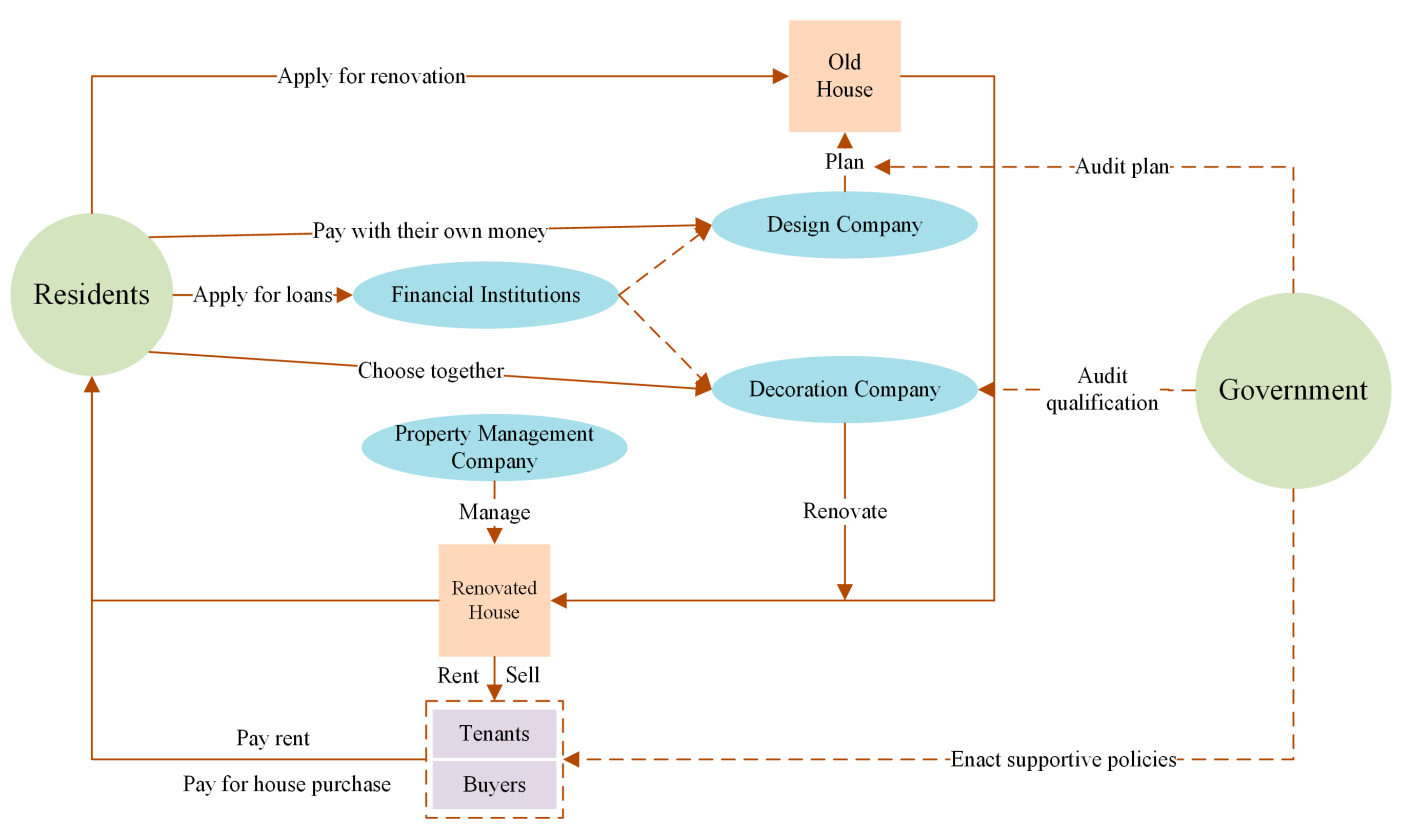

Figure 5. The platform for multi-stakeholder engagement in housing conservation and renovation.

Measure 5: Degressive subsidies.

Interviewees argued that HCR projects should be invested in by the government because urban heritage provides valuable cultural resources. However, they believe that residents should also invest because they are the ultimate beneficiaries. They proposed that, for HCR projects, government subsidies can be gradually reduced. Moreover, in the process of reducing subsidies, residents should be guided to invest. The main difficulty lies in eliminating residents' expectations; residents expect the continuation of "HD's high compensation" and "HCR's full subsidies" approaches. This can be addressed through outreach. Specifically, the Shanghai housing management department should provide an advance announcement of the proportion of government funding that will go toward HCR projects. They should then publicize the plan to residents through street offices. The outreach should emphasize that the government will reduce the proportion of government funding year by 
year; the remaining proportion must be raised by the residents themselves. In other words, the sooner residents apply for renovations, the higher the proportion of government funding will be. In addition, the government should grant subsidies to the elderly living alone and to families with low incomes (in line with the minimum living standard in Shanghai). The schematic diagram of degressive subsidies in HCR is shown in Figure 6. As time goes by, government subsidies will decrease, and residents will contribute more. This measure focuses on solving Challenge 1 ; it can also support Challenge 4.

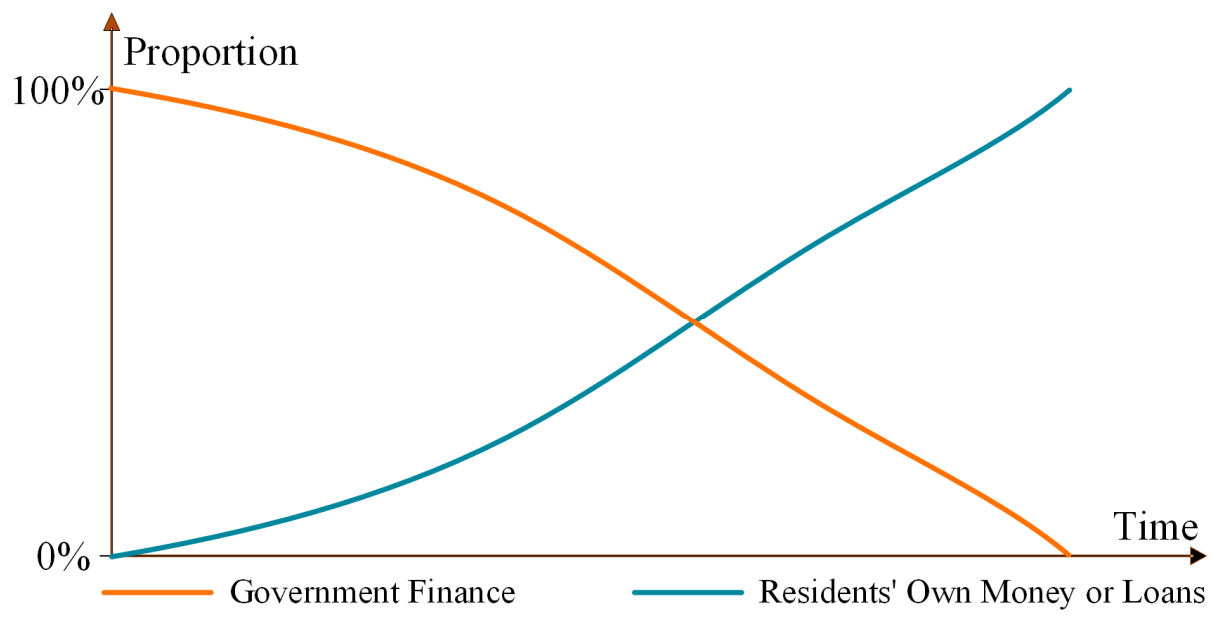

Figure 6. Degressive subsidies in housing conservation and renovation.

\section{Conclusions}

Under the double stimulation of housing reform and urban renewal in the last century, China has set off a wave of housing demolition. Some historic buildings were demolished. Therefore, HCR has been proposed and has received attention in China. This study investigates the most serious challenges faced by Shanghai HCR and proposes measures to address them. The first-hand data were collected using multiple approaches, including literature and regulation reviews, field investigations, and semistructured interviews. The field investigations were conducted in typical HCR pilot projects in Shanghai to obtain part of the first-hand data, and semistructured interviews were conducted to get the other part. Qualitative analysis was used via NVivo12 to process the data. The current HCR practices in Shanghai and key challenges in current practices were summarized. Some suggestions were also extracted. Based on these recommendations, group discussions and expert argumentation were held to draw up the final countermeasures.

Shanghai has invested significant effort into promoting HCR practice in the past few years. However, the transition from HD to HCR is slow, and some challenges remain. There are shortages in HCR funding, and the current regulations cannot effectively guide HCR project implementation. In addition, the high expropriation compensation in HD policy has created a large gap between reality and residents' psychological expectation. Furthermore, the HCR project lacks the involvement of multiple stakeholders. It is recommended that the government strengthen its leadership by developing guidelines for revising HD policy, breaking through current construction planning and FAR, screening housing, and implementing HCR. Moreover, the government is recommended to establish platforms for FAR trading and multi-stakeholder engagement. It is also suggested that HCR projects should adopt degressive subsidies. These countermeasures can help to support reductions in government fiscal expenditures, improvements in the current regulatory system, alleviation in the gap between reality and residents' psychological expectation, and engagements of multiple stakeholders. The results of this study can help Shanghai to promote HCR implementation and can be used by other cities in China with similar experiences. 
The main limitation of this study is that the measures proposed in this paper are only directional; these measures do not provide specific steps. Research is needed on each measure proposed in this study to formulate more specific and detailed implementation plans. In the future, other typical cities (such as Beijing and Guangzhou) could be investigated and more pilot projects could be undertaken to provide suggestions from a municipal and national perspective.

Author Contributions: Conceptualization, J.S. and X.M.; methodology, H.S.; resources, W.M.; data curation, X.M. and H.S.; writing - original draft preparation, X.M. and H.S.; writing—review and editing, D.T.; visualization, W.M.; supervision, J.S.; funding acquisition, J.S. and D.T.

Funding: This study was supported by the key research issue of Shanghai Municipal People's Government decision-making consultation (2018-A-024-A and 2019-A-025-B) and the National Social Science Foundation of China (19BGL274).

Acknowledgments: The authors wish to thank the anonymous reviewers, whose insightful comments and helpful suggestions significantly contributed to improving this paper.

Conflicts of Interest: The authors declare no conflict of interest.

\section{References}

1. Zhong, X.; Chen, X. Demolition, rehabilitation, and conservation: Heritage in Shanghai's urban regeneration, 1990-2015. J. Arch. Urban. 2017, 41, 82-91. [CrossRef]

2. Liu, X.; Huang, J.; Zhu, J. Property-rights regime in transition: Understanding the urban regeneration process in China-A case study of Jinhuajie, Guangzhou. Cities 2019, 90, 181-190. [CrossRef]

3. Wang, X.; Aoki, N. Paradox between neoliberal urban redevelopment, heritage conservation, and community needs: Case study of a historic neighbourhood in Tianjin, China. Cities 2019, 85, 156-169. [CrossRef]

4. Zhang, L. Contesting Spatial Modernity in Late-Socialist China. Curr. Anthropol. 2006, 47, 461-484. [CrossRef]

5. Zacharias, J.; Sun, Z.; Chuang, L.; Lee, F. The hutong urban development model compared with contemporary suburban development in Beijing. Habitat Int. 2015, 49, 260-265. [CrossRef]

6. Lorusso, S.; Cogo, G.M.; Natali, A. The protection and valorization of cultural and environmental heritage in the development process of the territory. Conserv. Sci. Cult. Herit. 2016, 16, 59-73.

7. Jiang, W.; Feng, T.; Timmermans, H.; Li, H. A gap-theoretical path model of residential satisfaction and intention to move house applied to renovated historical blocks in two Chinese cities. Cities 2017, 71, 19-29. [CrossRef]

8. Gu, H.; Ryan, C. Place attachment, identity and community impacts of tourism-the case of a Beijing hutong. Tour. Manag. 2008, 29, 637-647. [CrossRef]

9. Taylor, K. The Historic Urban Landscape paradigm and cities as cultural landscapes. Challenging orthodoxy in urban conservation. Landsc. Res. 2016, 41, 471-480. [CrossRef]

10. Jones, S. Wrestling with the Social Value of Heritage: Problems, Dilemmas and Opportunities. J. Community Archaeol. Herit. 2017, 4, 21-37. [CrossRef]

11. He, S.; Wu, F. Property-led redevelopment in post-reform China: A case study of Xintiandi redevelopment project in Shanghai. J. Urban. Aff. 2005, 27, 1-23. [CrossRef]

12. Yung, E.H.K.; Chan, E.H.W.; Xu, Y. Community-Initiated Adaptive Reuse of Historic Buildings and Sustainable Development in the Inner City of Shanghai. J. Urban Plan. Dev. 2013, 140, 05014003. [CrossRef]

13. Bandarin, F.; van Oers, R. The Historic Urban Landscape; John Wiley \& Sons: Hoboken, NJ, USA, 2012.

14. The Ministry of Natural Resources of Shanghai. Rule for Land Implementation of Urban Renewal Planning in Shanghai; The Ministry of Natural Resources of Shanghai: Shanghai, China, 2017.

15. Li, X.; Hui, E.C.M.; Chen, T.; Lang, W.; Guo, Y. From Habitat III to the new urbanization agenda in China: Seeing through the practices of the "three old renewals" in Guangzhou. Land Use Policy 2019, 81, 513-522. [CrossRef]

16. Tan, X.; Altrock, U. Struggling for an adaptive strategy? Discourse analysis of urban regeneration processes-A case study of Enning Road in Guangzhou City. Habitat Int. 2016, 56, 245-257. [CrossRef]

17. Zhang, L.; Chen, J.; Tochen, R.M. Shifts in governance modes in urban redevelopment: A case study of Beijing's Jiuxianqiao Area. Cities 2016, 53, 61-69. [CrossRef] 
18. Ginzarly, M.; Houbart, C.; Teller, J. The Historic Urban Landscape approach to urban management: A systematic review. Int. J. Herit. Stud. 2018. [CrossRef]

19. Junhua, L. Beijing's old and dilapidated housing renewal. Cities 2002, 14, 59-69. [CrossRef]

20. He, S.; Wu, F. China's emerging neoliberal urbanism: Perspectives from urban redevelopment. Antipode 2009, 41, 282-304. [CrossRef]

21. Shih, M. The evolving law of disputed relocation: Constructing inner-city renewal practices in Shanghai, 1990-2005. Int. J. Urban Reg. Res. 2010, 34, 350-364. [CrossRef]

22. Yang, Y.R.; Chang, C.H. An urban regeneration regime in China: A case study of urban redevelopment in Shanghai's Taipingqiao Area. Urban Stud. 2007, 44, 1809-1826. [CrossRef]

23. Healey, P. Urban Regeneration and the Development Industry. Reg. Stud. 1991, 25, 97-110. [CrossRef]

24. He, S.; Wu, F. Socio-spatial impacts of property-led redevelopment on China's urban neighbourhoods. Cities 2007, 24, 194-208. [CrossRef]

25. Egan, M.; Lawson, L.; Kearns, A.; Conway, E.; Neary, J. Neighbourhood demolition, relocation and health. A qualitative longitudinal study of housing-led urban regeneration in Glasgow, UK. Health Place 2015, 33, 101-108. [CrossRef]

26. Paredes, D.; Skidmore, M. The net benefit of demolishing dilapidated housing: The case of Detroit. Reg. Sci. Urban Econ. 2017, 66, 16-27. [CrossRef]

27. Wang, J.; Wu, H.; Duan, H.; Zillante, G.; Zuo, J.; Yuan, H. Combining life cycle assessment and Building Information Modelling to account for carbon emission of building demolition waste: A case study. J. Clean. Prod. 2016, 172, 3154-3166. [CrossRef]

28. Yu, T.; Shen, G.Q.; Shi, Q.; Zheng, H.W.; Wang, G.; Xu, K. Evaluating social sustainability of urban housing demolition in Shanghai, China. J. Clean. Prod. 2017, 153, 26-40. [CrossRef]

29. Shin, H.B. Urban conservation and revalorisation of dilapidated historic quarters: The case of Nanluoguxiang in Beijing. Cities 2010, 27, S43-S54. [CrossRef]

30. Yu, T.; Shen, G.Q.; Shi, Q.; Lai, X.; Li, C.Z.; Xu, K. Managing social risks at the housing demolition stage of urban redevelopment projects: A stakeholder-oriented study using social network analysis. Int. J. Proj. Manag. 2017, 35, 925-941. [CrossRef]

31. Liu, L.; Xu, Z. Collaborative governance: A potential approach to preventing violent demolition in China. Cities 2018, 79, 26-36. [CrossRef]

32. Keene, D.E.; Ruel, E. "Everyone called me grandma": Public housing demolition and relocation among older adults in Atlanta. Cities 2013, 35, 359-364. [CrossRef] [PubMed]

33. The Central Committee of Communist Party of China and the State Council. Suggestion on Further Strengthening the Management of Urban Planning and Construction by the Central Committee of Communist Party of China and the State Council; The Central Committee of Communist Party of China and the State Council: Beijing, China, 2016.

34. Han, H.; Shu, X.; Ye, X. Conflicts and regional culture: The general features and cultural background of illegitimate housing demolition in China. Habitat Int. 2018, 75, 67-77. [CrossRef]

35. State Council of the People's Republic of China. List of National Famous Historical and Cultural Cities; State Council of the People's Republic of China: Beijing, China, 2010.

36. Ye, L. Urban regeneration in China: Policy, development, and issues. Local Econ. 2011, 26, 337-347. [CrossRef]

37. Baldwin, A.N.; Loveday, D.L.; Li, B.; Murray, M.; Yu, W. A research agenda for the retrofitting of residential buildings in China-A case study. Energy Policy 2018, 113, 41-51. [CrossRef]

38. Zhu, G. China's architectural heritage conservation movement. Front. Archit. Res. 2012, 1, 10-22. [CrossRef]

39. González Martínez, P. Authenticity as a challenge in the transformation of Beijing's urban heritage: The commercial gentrification of the Guozijian historic area. Cities 2016, 59, 48-56. [CrossRef]

40. UNESCO. Recommendation on the historic urban landscape. In Proceedings of the UNESCO. General Conference, 36th, Paris, France, 25 October-10 November 2011.

41. Chang, T.C.; Teo, P. The shophouse hotel: Vernacular heritage in a creative city. Urban Stud. 2009, 46, $341-367$. [CrossRef]

42. Hani, U.; Azzadina, I.; Sianipar, C.P.M.; Setyagung, E.H.; Ishii, T. Preserving Cultural Heritage through Creative Industry: A Lesson from Saung Angklung Udjo. Procedia Econ. Financ. 2013, 4, 193-200. [CrossRef]

43. Chen, F. Traditional architectural forms in market oriented Chinese cities: Place for localities or symbol of culture? Habitat Int. 2011, 35, 410-418. [CrossRef]

44. United Nations. Sustainable Development; Agenda 21; United Nations: Rio de Janerio, Brazil, 1992. 
45. Verdini, G. Is the incipient Chinese civil society playing a role in regenerating historic urban areas? Evidence from Nanjing, Suzhou and Shanghai. Habitat Int. 2015, 50, 366-372. [CrossRef]

46. Mehrpoya, H.; Khuonbazi, V.; Ahouei, S. A comparison of "identity" in vernacular (traditional) and contemporary (modern) houses. J. Sci. Res. Dev. 2015, 2, 309-315.

47. Wai, A.W.T. Place promotion and iconography in Shanghai's Xintiandi. Habitat Int. 2006, 30, $245-260$. [CrossRef]

48. Guccio, C.; Mazza, I. On the political determinants of the allocation of funds to heritage authorities. Eur. J. Political Econ. 2014, 34, 18-38. [CrossRef]

49. Fung, I.W.H.; Tsang, Y.T.; Tam, V.W.Y.; Xu, Y.T.; Mok, E.C.K. A review on historic building conservation: A comparison between Hong Kong and Macau systems. Renew. Sustain. Energy Rev. 2017, 71, 927-942. [CrossRef]

50. González Martínez, P. Urban authenticity at stake: A new framework for its definition from the perspective of heritage at the Shanghai Music Valley. Cities 2017, 70, 55-64. [CrossRef]

51. Wang, H.J.; Lee, H.Y. How government-funded projects have revitalized historic streetscapes-Two cases in Taiwan. Cities 2008, 25, 197-206. [CrossRef]

52. Theodossopoulos, D. Nineteenth-century housing preventive conservation in Edinburgh and its Western European context. J. Cult. Herit. Manag. Sustain. Dev. 2018, 8, 95-110. [CrossRef]

53. Hung, H. Governance of built-heritage in a restrictive political system: The involvement of non-governmental stakeholders. Habitat Int. 2015, 50, 65-72. [CrossRef]

54. Zhuang, T.; Qian, Q.K.; Visscher, H.J.; Elsinga, M.G.; Wu, W. The role of stakeholders and their participation network in decision-making of urban renewal in China: The case of Chongqing. Cities 2019, 92, 47-58. [CrossRef]

55. Edhlund, B.; McDougall, A. NVivo 11 Essentials; Lulu Press, Inc.: Morrisville, NC, USA, 2019.

56. Sepasgozar, S.M.E.; Davis, S. Construction Technology Adoption Cube: An Investigation on Process, Factors, Barriers, Drivers and Decision Makers Using NVivo and AHP Analysis. Buildings 2018, 8, 12-15. [CrossRef]

57. Feng, X.; Behar-horenstein, L. Maximizing NVivo Utilities to Analyze Open-Ended Responses. Qual. Rep. 2019, 24, 563-571.

58. Hongkou District Finance Bureau Hongkou District 2017 Financial Final Accounts (Draft). Available online: http://xxgk.shhk.gov.cn/hkxxgk/Depart/showinfo.aspx?InfoID=36234af2-f710-46fc-a6b9dc61f20c55ea\&CategoryNum=002002001001001\&DeptCode $=$ (accessed on 7 April 2019).

59. Amin, H.M.T.M.; Adu-Ampong, E.A. Challenges to urban cultural heritage conservation and management in the historic centre of Sulaimaniyah, Kurdistan-Iraq. J. Cult. Herit. Manag. Sustain. Dev. 2016, 6, 225-270.

60. Yan, J.; Bao, H.X.H. A prospect theory-based analysis of housing satisfaction with relocations: Field evidence from China. Cities 2018, 83, 193-202. [CrossRef]

61. He, B.J.; Zhao, D.X.; Zhu, J.; Darko, A.; Gou, Z.H. Promoting and implementing urban sustainability in China: An integration of sustainable initiatives at different urban scales. Habitat Int. 2018, 82, 83-93. [CrossRef]

62. Beijing Cailiang Law Firm. 2017: Annual Report of Urban. Housing Demolition in China; Beijing Cailiang Law Firm: Beijing, China, 2018.

63. Xilin, L.U.; Wensheng, L.U.; Xin, Z. New Resolution for Historic Building Conservation by Building Moving Technology. Adv. Mater. Res. 2010, 134, 19-25.

64. Wu, J.; Wu, Y.; Yu, W.; Lin, J.; He, Q. Residential landscapes in suburban China from the perspective of growth coalitions: Evidence from Beijing. J. Clean. Prod. 2019, 223, 620-630. [CrossRef]

65. Wang, A.; Hu, Y.; Li, L.; Liu, B. Group Decision Making Model of Urban Renewal Based on Sustainable Development: Public Participation Perspective. Procedia Eng. 2016, 145, 1509-1517. [CrossRef]

66. Zhang, F.; Zhang, C.; Hudson, J. Housing conditions and life satisfaction in urban China. Cities 2018, 81, 35-44. [CrossRef]

(C) 2019 by the authors. Licensee MDPI, Basel, Switzerland. This article is an open access article distributed under the terms and conditions of the Creative Commons Attribution (CC BY) license (http://creativecommons.org/licenses/by/4.0/). 